\title{
CAD/CAM Customized Glass Fiber Post and Core With Digital Intraoral Impression: A Case Report
}

\section{Antonio Libonati \\ Virginia Di Taranto (D) \\ Gianni Gallusi \\ Edoardo Montemurro \\ Vincenzo Campanella}

Department of Clinical Sciences and Translational Medicine, University Tor Vergata, Rome, Italy

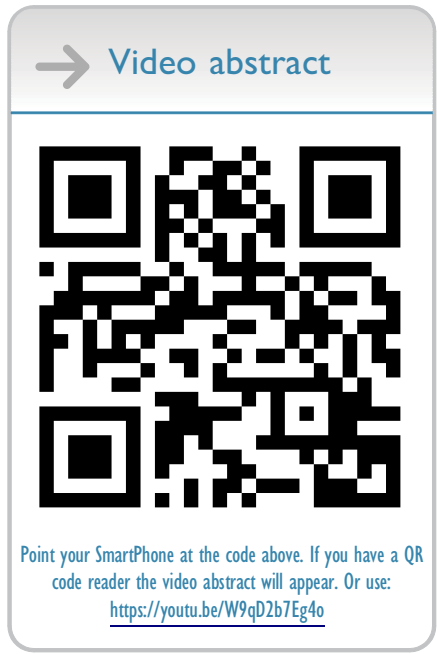

Correspondence: Virginia Di Taranto Department of Clinical Sciences and Translational Medicine, University of Rome Tor Vergata, Viale Oxford, 8I,

Rome, IT 00133, Italy

Tel +390620900396

Email virginia.ditaranto@gmail.com
This article was published in the following Dove Press journal:

Clinical, Cosmetic and Investigational Dentistry

Background: After endodontic treatment, a proper restorative technique is necessary to ensure coronal seal and protection of residual dental structure; teeth which have lost two or more walls need to be restored with posts to increase retention and stability of final restoration. Posts can be distinguished in prefabricated and customized, which are manufactured by lost wax technique or CAD-CAM.

Purpose: Digital dentistry has been developed to increase workflow precision and to accelerate production process; use of CAD-CAM to realize customized posts was limited to scanning plaster models obtained from traditional impressions.

Patients and Methods: In the reported case an intraoral scan was used to mill a post and core restoration on an endodontically treated inferior premolar; this operative protocol was based on previous in vitro experiments that confirmed the ability of 3 shape Trios scanner to read post-space up to $9 \mathrm{~mm}$ in depth.

Results: The digital technique allows us to convert the concave surface of the root canal into the convex surface of the post, and realize an anatomical post and core that improves the biomechanics of the endodontically treated tooth reducing the possibility of root fractures.

Conclusion: The use of an intraoral digital scanner represents an opportunity for the clinician as it speeds up the production of an anatomical post and core restorations.

Keywords: digital dentistry, endodontic, post-space, digital intraoral impression, post and core

\section{Introduction}

Endodontically treated teeth are well known to be more susceptible to fracture. ${ }^{1}$ This is due to the loss of hard tissues coming from the sum of an initial carious pathology, ${ }^{2}$ the endodontic access cavity and instrumentation and finally, for a minimal part, for the biochemical and structural changes in nonvital dentin. ${ }^{3}$ Also, saliva due to an important role in microbial oral flora regulation. ${ }^{4-6}$

After endodontic treatment, a proper restorative technique is necessary to ensure coronal seal ${ }^{7,8}$ and protection of residual dental structure; ${ }^{9}$ teeth which have lost two or more walls need to be restored with posts to increase retention and stability of final restoration. $^{10-12}$

Several materials have been proposed to build posts; metallic posts belong to I and II generations, fiber, ceramic and zirconium oxide are III and IV generations.

Moreover, posts can be distinguished in prefabricated and customized, which are manufactured by lost wax technique or CAD-CAM.

In comparison to rigid metal and/or ceramic posts, fiber posts do have better biomechanical behavior because their physical properties are closer to natural dentin ${ }^{13}$ allowing for a better distribution of occlusal forces and reducing substantially, if compared with harder materials, the risk of vertical root fracture. ${ }^{14,15}$ 
Some authors suggested, in a finite element analysis study, that the ideal post should have a variable elastic modulus related to the depth into the root as this could reduce significantly stress concentration. ${ }^{16}$

The use of custom prepared posts (or post and cores) allows for a very thin layer of cementing resin thus providing a good way to reduce drastically polymerization stresses and gaps or voids formation in the adhesive interface. ${ }^{17,18}$

The modern idea of a customized post and core calls for conservation of root dentin with minimal or no preparation of a post-space thus resulting in thicker dentin walls and increased resistance to root fracture and ease of core restoration. ${ }^{19}$

In the past years, several attempts to customize prefabricated posts have been done by subtractive or additive ways; ${ }^{20,21}$ this "hand-made" approach could be surpassed by CAD-CAM technology. ${ }^{22,23}$

Digital dentistry has been developed to increase workflow precision and to accelerate the production process; ${ }^{24-26}$ generally, use of CAD-CAM to realize customized posts was limited to scanning plaster models obtained from traditional impressions. ${ }^{27-29}$ Other authors purposed a different digital workflow in which a traditional silicon impression is scanned to mill a personalized CAD-CAM post and core. ${ }^{30}$ Differently, in the reported case an intraoral scan of post-space was performed; this operative protocol is the outcome of in vitro experiments about the capacity of 3 shape Trios scanner to read post-space in order to obtain a full digital workflow. The preliminary in vitro study ${ }^{31}$ showed that the scanner is able to read down to a depth of $9 \mathrm{~mm}$ in the root canal which is a good compromise and adapts to most clinical cases.

In the presented case report a customized glass fiber post and core obtained using this protocol were cemented with adhesive technique and the tooth restored with monolithic zirconia crown also realized by CAD-CAM.

\section{Materials and Methods}

A 55-years-old female patient came to the EmergencyRestorative and Endodontic Dental Department of the Tor Vergata University Polyclinic asking for prosthetic rehabilitation of the right inferior second premolar. The patient provided a written informed consent to publish details and any images about this case report. Institutional approval was not required for the publication of this case report.

Radiographic examinations, panoramic Xray and intraoral periapical projection showed inadequate root canal treatment of 4.5 (Figure 1). Taking into account the age of the patient, low masticatory forces, the residual root dentinal thickness and the height of the clinical crown related to

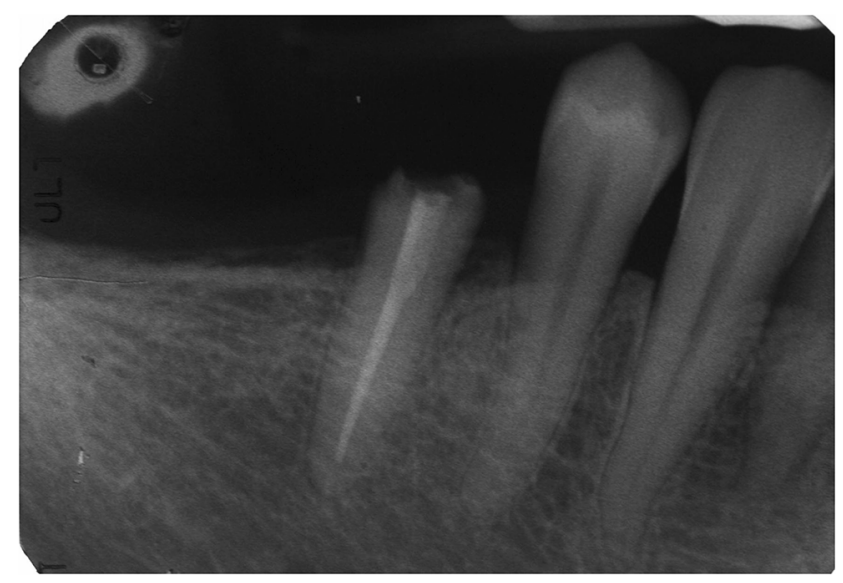

Figure I Preoperative periapical radiography, inappropriate root canal treatment of 4.5 and a periapical lesion.

total length of root; the selected treatment plan was: endodontic retreatment of 4.5 and crown restoration by customized glass fiber post and core and monolithic zirconia crown. Even if the tooth had a reduced periodontal support a $9 \mathrm{~mm}$ post depth together with a $2.5 \mathrm{~mm}$ dentinal ferrule for the prosthetic crown ware judged a viable restorative option preserving root dentin from too deep post preparations.

Firstly, endodontic retreatment was performed. After local anesthesia $^{32,33}$ and insulation with rubber dam, access cavity was obtained by truncated cone shape diamond bur, root canal patency was obtained with size $10 \mathrm{~K}$-file (Dentsply, Sirona, USA) using Endosolv E (Septodont) and working length was established to be $16 \mathrm{~mm}$ with electronic apex locator (Dental Root ZX, Morita Corporation, Japan). Then, the treated root canal was shaped using Mtwo technique (Sweden and Martina, Italy) (basic sequence: 10.04/15.05/20.06/25.06) and preparation was completed with manual instruments in the apical zone (k-file 45 to working length, 50 to $0.5 \mathrm{~mm}$ from the foramen and 55 to $1 \mathrm{~mm}$ ). The root canal was filled with warm guttapercha using the Microheat technique (Sweden and Martina) with a master cone size 55 , taper $02,1 \mathrm{~mm}$ short than working length followed by mechanically packed warm guttapercha.

Subsequently, post-space was prepared using Mtwo 55/ 06 post-file, which removes effectively guttapercha from the canal with minor modifications of the shaped root canal, allowing an anatomical conservative approach.

The post-space was prepared $9 \mathrm{~mm}$ in depth, ensuring maintenance of a $6-7 \mathrm{~mm}$ gutta-percha apical seal, and $3 \mathrm{~d}$ scanned using a Trios (3shape) intraoral scanner. The preparation depth has been established in relation to an in vitro preliminary study about the capacity of Trios scanner to read post-spaces (Figure 2). 


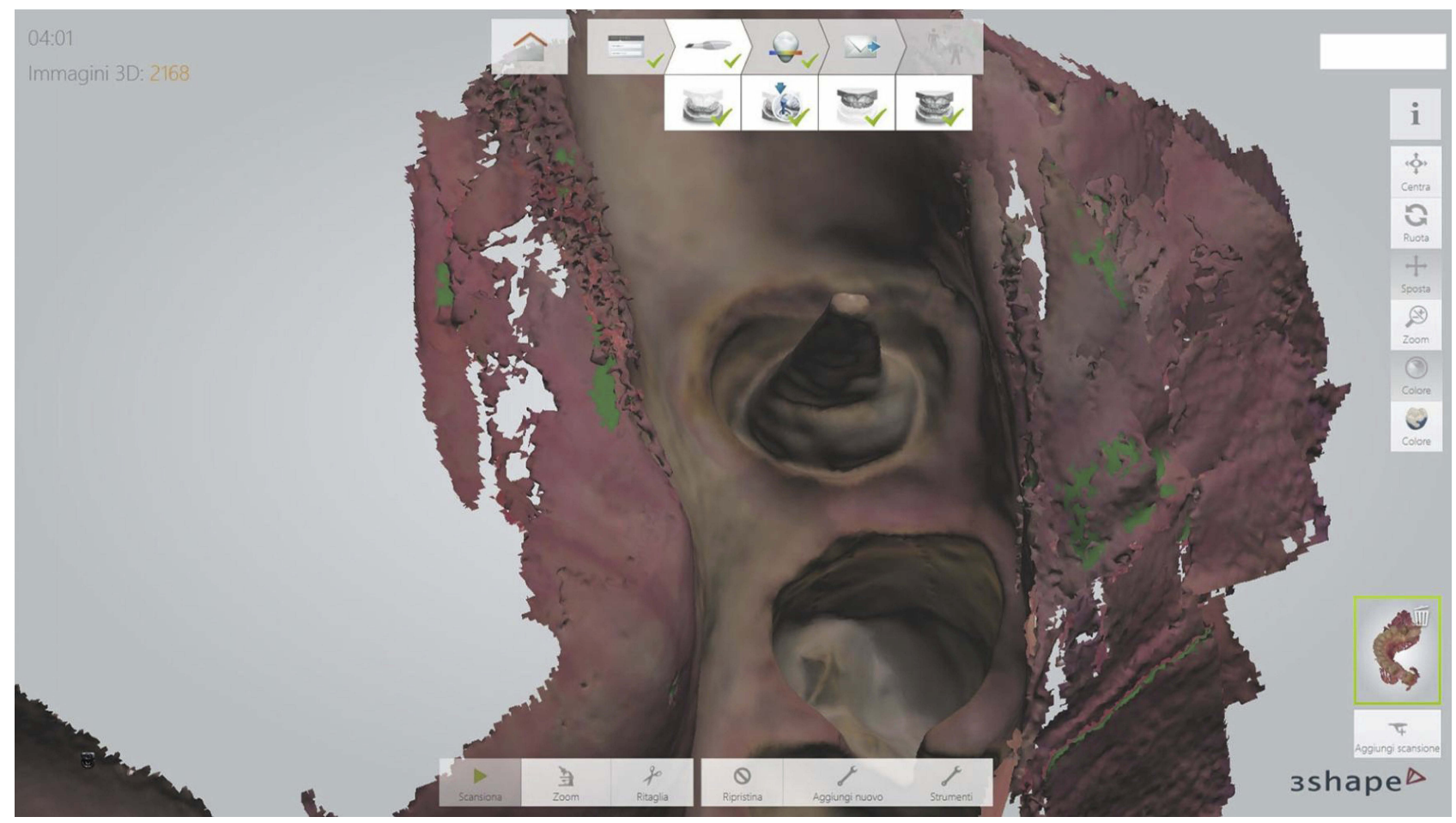

Figure 2 The post-space was prepared $9 \mathrm{~mm}$ in depth. It has been scanned by Trios 3shape scanner: 3D software images.

The intraoral scan included post-space and crown preparation of 4.5 in a full lower and upper arches digital imprint and a left and right bite registration.

After processing $3 \mathrm{~d}$ images and CAD design of the pieces a custom glass fiber post and core (Trilor Bioloren, Saronno, VA, Italy $)^{34}$ was manufactured by a CAM milling machine (Roland DWX-50, Irvine, CA, USA) ${ }^{35}$ as well as a provisional composite resin crown (Figures 3 and 4). Trilor was chosen as it is a multidirectional fiber-reinforced resin material approved for definitive CAD-CAM prosthetic appliances and its mechanical characteristics are close to

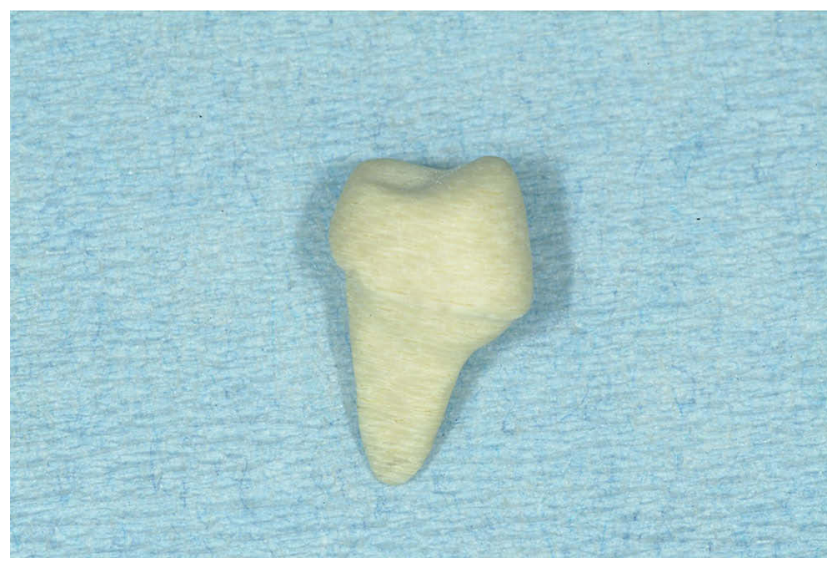

Figure 3 Photography of post and core. natural dentin as it has an elastic modulus of 26GPa (manufacturer data) and it was purposed as a promising material by Ruschel et al in $2018 .{ }^{36}$

Due to the geometry of the piece, the milling of a post and core system requires a slower and a low-stress machining procedure in order to reduce vibrations, inaccuracy or failure of the machining process. For these reasons, the milling machine used for this application is a five-axis milling machine set for a high-quality slow speed procedure that required almost 30 mins of work for the piece. ${ }^{35}$

The milled post and core was realized with $80 \mu \mathrm{m}$ tolerances to ensure a proper fit without interfering with cementation procedures. ${ }^{34}$ After fitting and adaptation check to ensure the necessity of only a light force to complete sitting, no adjustment was needed, the surface of the custom post to be cemented was cleaned, etched with $37 \%$ orthophosphoric acid (Ivoclar Vivadent, Italy) and silanized (Monobond Plus Ivoclar Vivadent, Italy) to prepare it for the following adhesive procedures. ${ }^{37}$

All dental surfaces were pretreated for adhesive procedures with $37 \%$ orthophosphoric acid (Ivoclar Vivadent, Italy). Etch and rinse adhesive Prime\&Bond NT (Dentsply Sirona, USA) was used on a dental substrate and on the post and core and light cured following manufacturer indications. 


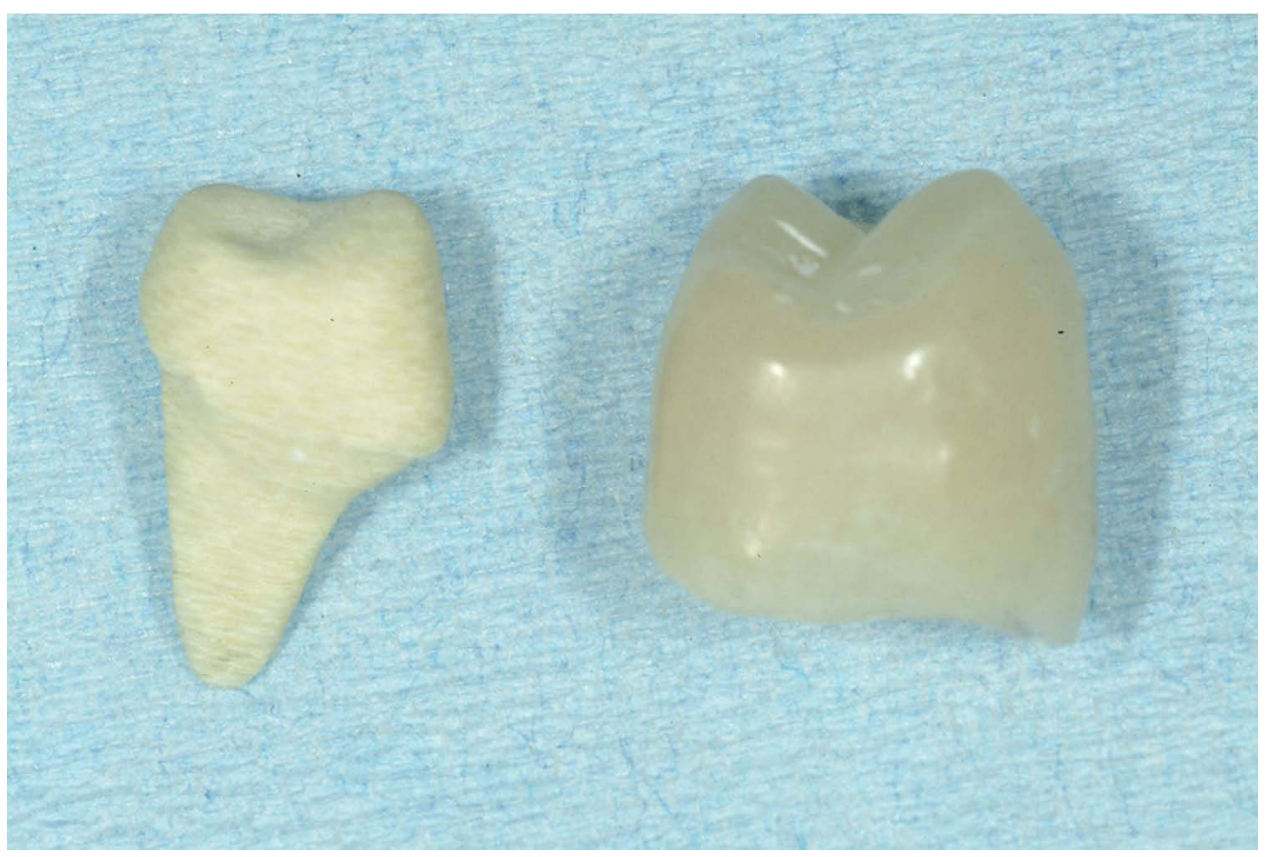

Figure 4 Photography of post and core, and provisional composite resin crown.

The custom post and core were cemented with Precision Cement One (Dentalica, Italy), a dual-cure composite cement (Figures 5 and 6). After cementation and finishing of the resulting prosthetic preparation, the milled provisional resin crown was cemented on the tooth to regain function waiting for a final digital impression for the zirconia final crown (Figure 7).

Tree weeks after post and core cementation, a second and final digital impression was performed to allow the lab to realize a monolithic zirconia crown; gingival retraction cords (Ultrapack $\# 000$ and $\# 00$, Ultradent, USA) have been used to expose margin preparation (Figures 8-10).

Finally, the monolithic zirconia crown was cemented using Harvard zinc phosphate cement (Harvard

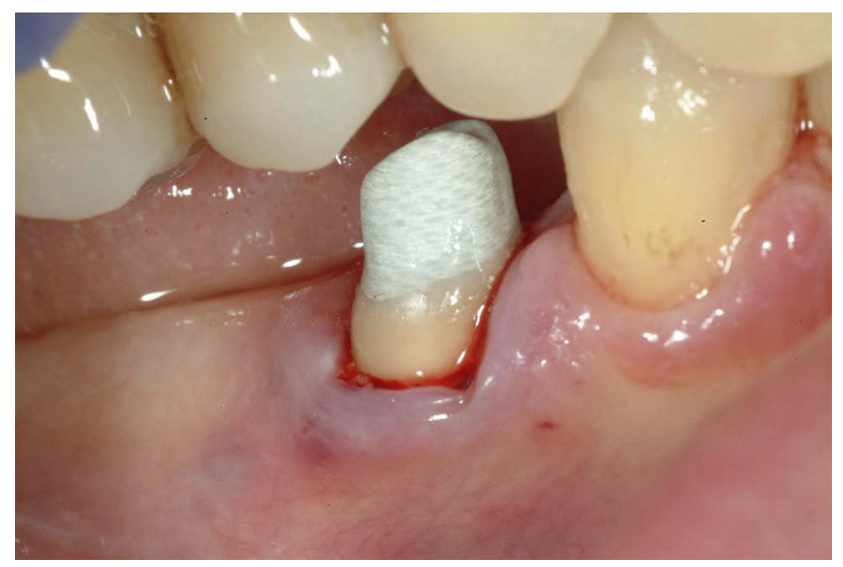

Figure 5 Intraoral vision of post and core after adhesive cementation.

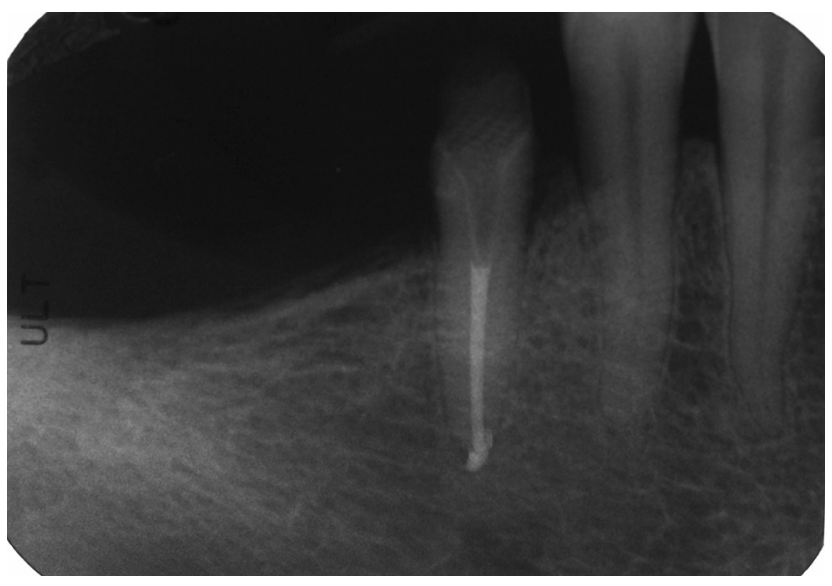

Figure 6 Postoperative periapical radiography, the endodontic retreatment was performed, and the post and core have been luted.

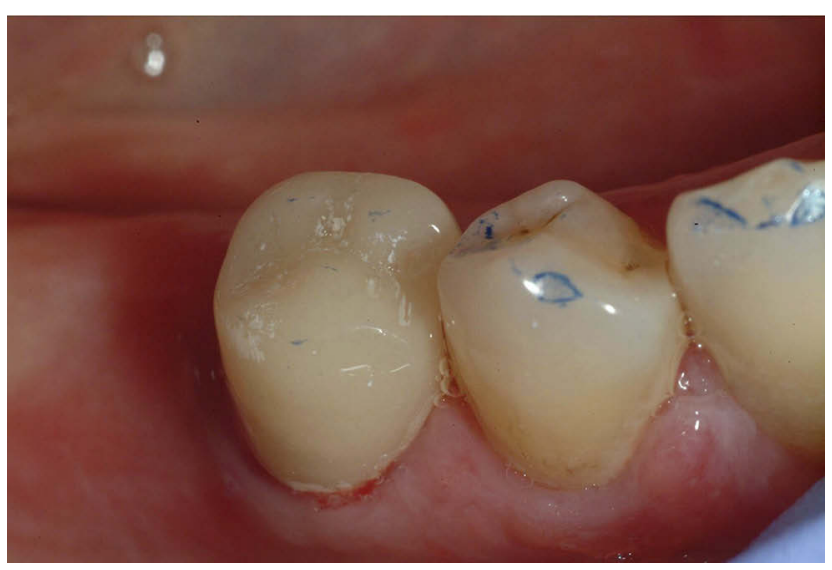

Figure 7 Intraoral photography after provisional composite resin crown cementation. 


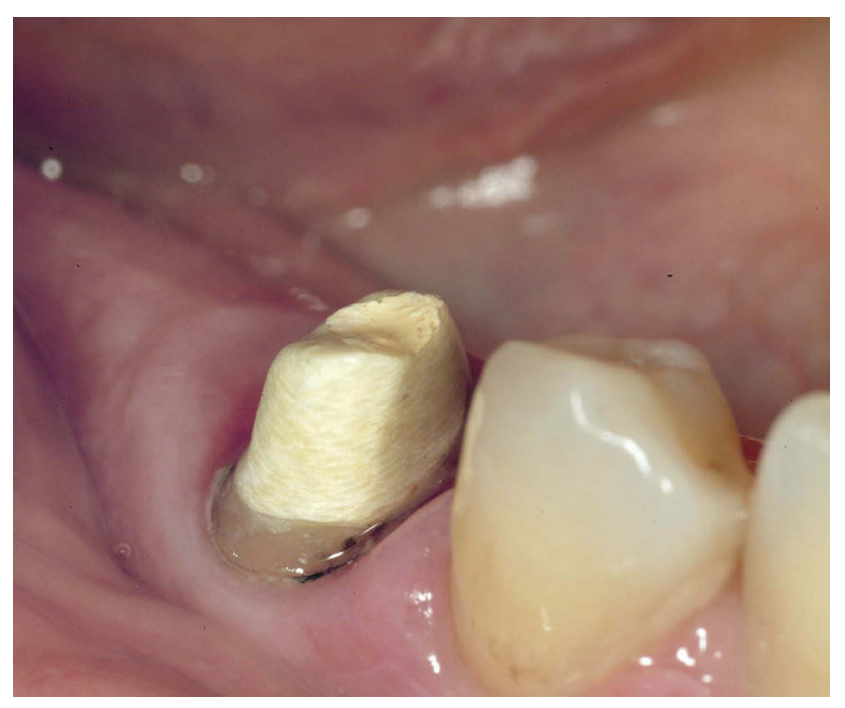

Figure 8 Intraoral photography after digital impression with Trios 3shape scanner.

Dental, Germany) completing the rehabilitation protocol (Figures 11 and 12).

Due to economic concerns, posterior missing teeth in the lower arch were replaced with a removable partial prosthetic (Figure 13). Figure 14 shows a follow-up intraoral radiograph of the restored tooth after 2years of function and clinical success.

\section{Results}

The digital technique allows us to convert the concave surface of the root canal into the convex surface of the post, and realize, as reported in the literature, ${ }^{27}$ an anatomical post and core that improves the biomechanics of the endodontically treated tooth reducing the possibility of root fractures.

Digital procedures allow to create prosthetic products, posts and post and cores, in direct or semi-direct technique; ${ }^{38}$ it is possible to scan a polyvinylsiloxane (PVS) impression of a post-space, or scan the Duralay imprint, but these techniques require more working steps which lead to a risk of procedural errors.

The direct technique is considered more accurate, in terms of trueness and precision (ISO), ${ }^{39}$ to produce prosthetic products through the digital work-flow. The digital workflow allows the use of industrially precured fiberreinforced composite resins with superior mechanical properties.

The precision of the CAD/CAM post and core restoration allows for a minimal amount of cementing composite resin and can result in a better adhesion to the dentinal walls. ${ }^{31}$

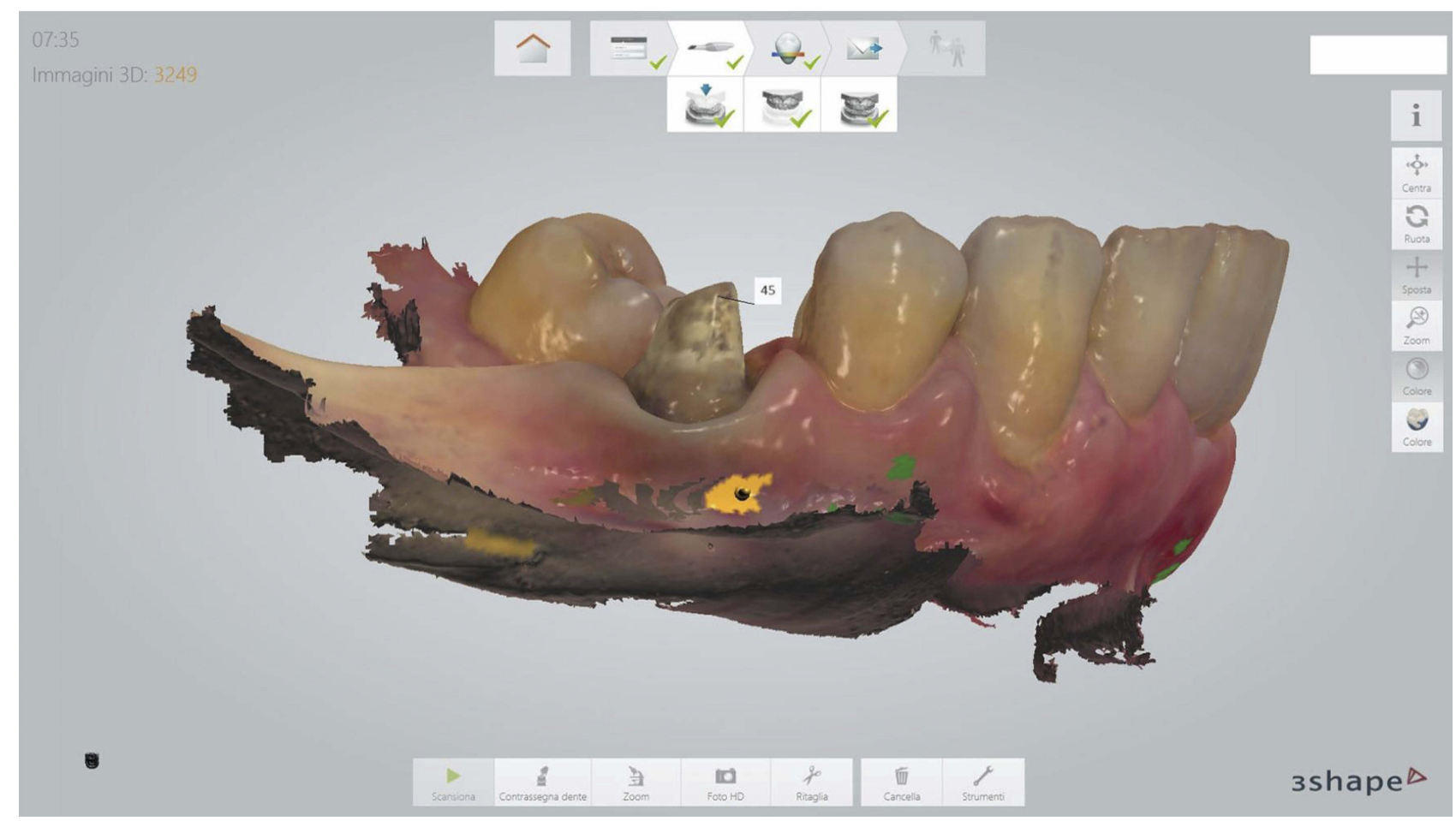

Figure 9 Final digital impression with Trios 3shape scanner. 


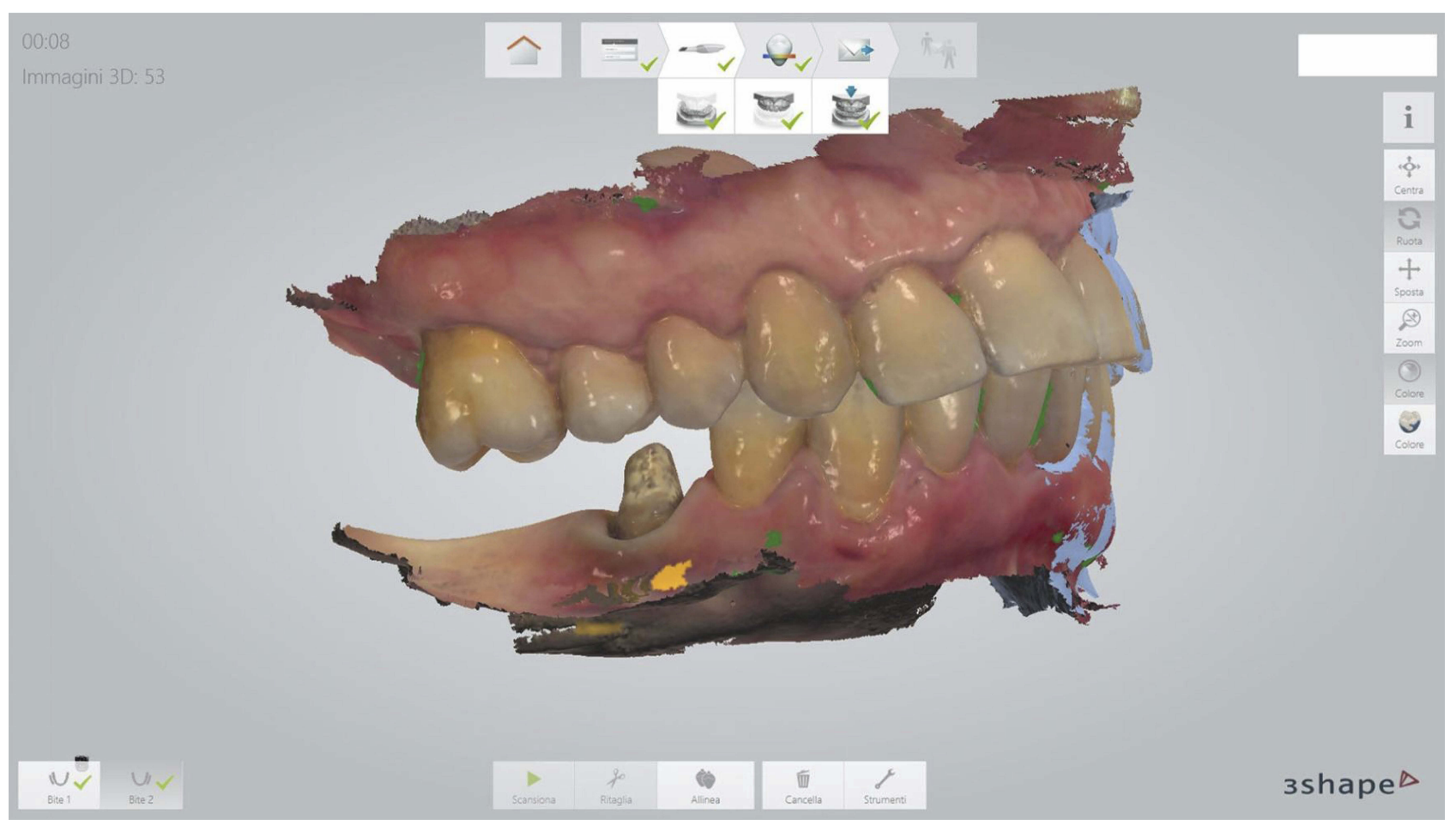

Figure 10 Final digital impression with Trios 3shape scanner, right bite.

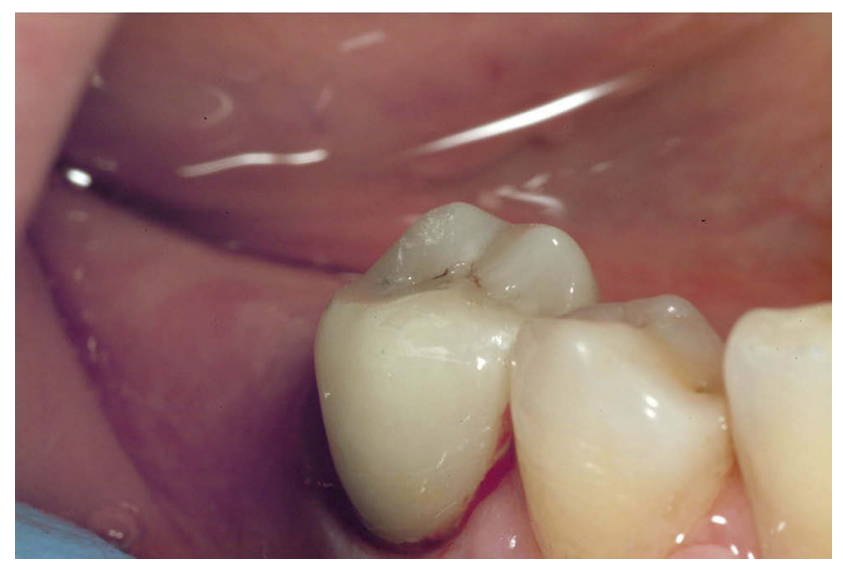

Figure I I Intraoral photography of monolithic zirconia crown after cementation.

The use of an intraoral digital scanner is capable of a high precision fitting of the milled post and core and full crown restorations much quickly and directly than more complexes lab scanning of traditional imprints.

\section{Conclusion}

The use of an intraoral digital scanner represents an opportunity for the clinician as it speeds up the production of an anatomical post and core restorations.

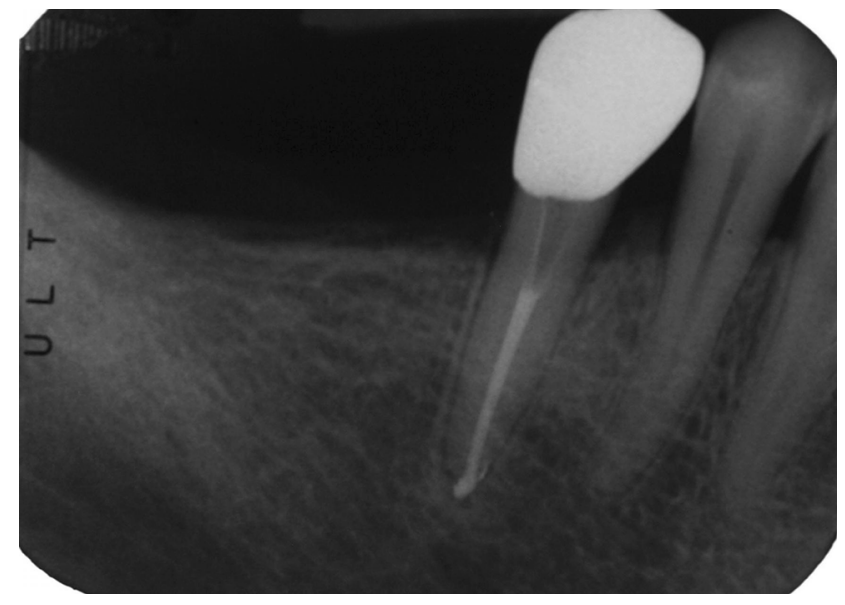

Figure 12 Periapical radiography, the monolithic zirconia crown has been luted definitively.

The use of glass fiber resin to produce a precise customized post and core, an effective adhesive cementation and a thin cement layer with reduced curing stress, is promising in order to obtain a tooth-restoration system with more favorable resistance to biomechanical stresses. Further case series and in vitro research are needed to standardize the technique as many new CAD-CAM materials will be available in the future giving the clinicians many new treatment opportunities. 


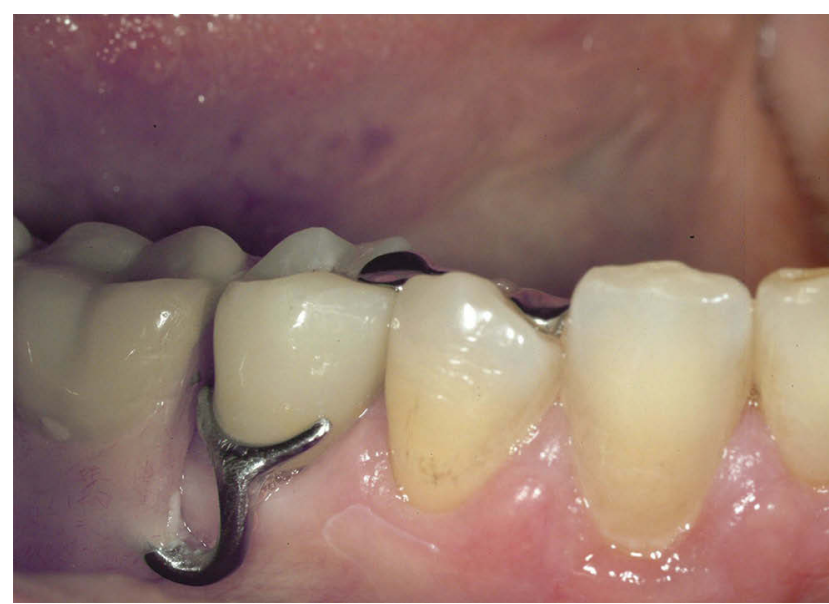

Figure 13 Intraoral final photography with a removable partial prosthetic.

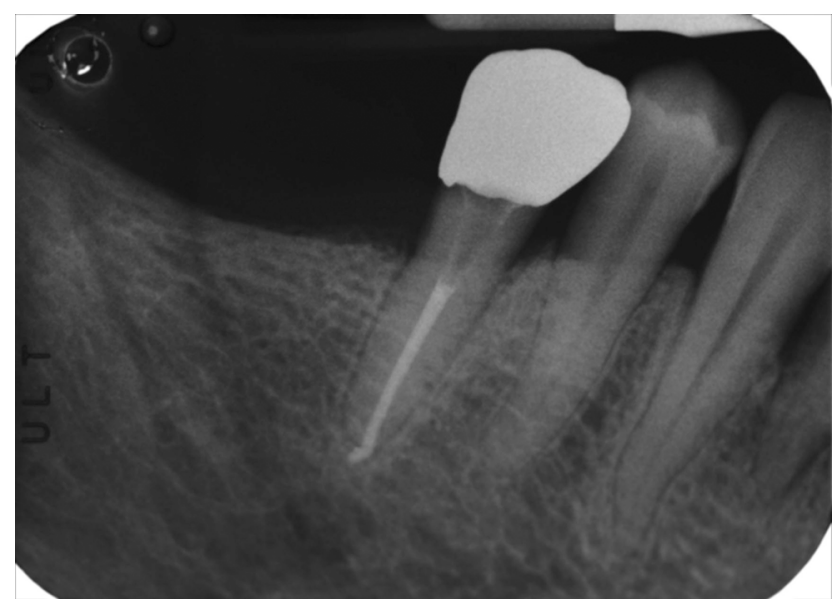

Figure 14 Two years control periapical radiography of the functional and clinically successful treated tooth.

\section{Abbreviations}

CAD, Computer-assisted-design; CAM, Computer-assistedmanufacturing; PVS, polyvinylsiloxane.

\section{Disclosure}

The authors report no conflicts of interest in this work.

\section{References}

1. Dietschi D, Duc O, Krejci I, Sadan A. Biomechanical considerations for the restoration of endodontically treated teeth: a systematic review of the literature, Part II (Evaluation of fatigue behavior, interfaces, and in vivo studies). Quintessence Int. 2008;39(2):117-129.

2. Albani F, Ballesio I, Campanella V, Marzo G. Pit and fissure sealants: results at five and ten years. Eur J Paediatr Dent. 2005;6(2):61-65.

3. Nagasiri R, Chitmongkolsuk S. Long-term survival of endodontically treated molars without crown coverage: a retrospective cohort study. $J$ Prosthet Dent. 2005;93:164-170. doi:10.1016/j.prosdent.2004.11.001
4. Ortu E, Sgolastra F, Barone A, Gatto R, Marzo G, Monaco A. Salivary streptococcus mutans and Lactobacillus spp. levels in patients during rapid palatal expansion. Eur J Paediatr Dent. 2014;15(3):271-274.

5. Marchetti E, Tecco S, Caterini E, et al. Alcohol-free essential oils containing mouth rinse efficacy on three-day supragingival plaque regrowth: a randomized crossover clinical trial. Trials. 2017;18:7380. doi:10.1186/s13063-017-1901-z

6. Mummolo S, Nota A, Caruso S, Quinzi V, Marchetti E, Marzo G. Salivary markers and microbial flora in mouth breathing late adolescents. Biomed Res Int. 2018;2018:8687608. doi:10.1155/2018/8687608

7. Libonati A, Montemurro E, Nardi R, Campanella V. Percentage of gutta-percha-filled areas in canals obturated by 3 different techniques with and without the use of endodontic sealer. J Endod. 2018;44 (3):506-509. doi:10.1016/j.joen.2017.09.019

8. Libonati A, Di Taranto V, D Agostini C, et al. Comparison of coronal leakage of different root canal filling techniques: an ex vivo study. $J$ Biol Regul Homeost Agents. 2018;32(2):397-405.

9. Campanella V, Di Taranto V, Libonati A, et al. Indirect adhesive rehabilitation by cementation under pressure of a case of Dentinogenesis Imperfecta type II: follow-up after 13 years. Eur J Paediatr Dent. 2018;19(4):303-306. doi:10.23804/ejpd.2018.19.04.10

10. Zicari F, Couthino E, De Munck J, et al. Bonding effectiveness and sealing ability of fiber-post bonding. Dent Mater. 2008;24:967-977. doi:10.1016/j.dental.2007.11.011

11. Libonati A, Marzo G, Klinger FG, et al. Embryotoxicity assays for leached components from dental restorative materials. Reprod Biol Endocrinol. 2011;9:136. doi:10.1186/1477-7827-9-136

12. Ballesio I, Angotti V, Gallusi G, et al. Durability of adhesion between an adhesive and post-space dentin: push-out evaluation at one and six months. Int $J$ Adhes and Adhes. 2012;38:75-78. doi:10.1016/j. ijadhadh.2012.05.001

13. Bru E, Forner L, Llena C, Almenar A. Fiber post behaviour prediction factors. A review of the literature. J Clin Exp Dent. 2013;5: e150-e153. doi:10.4317/jced.50619

14. Lassila LVJ, Tanner J, Le Bell AM, Narva K, Vallittu PK. Flexural properties of fiber reinforced root canal posts. Dent Mater. 2004;20:29-36. doi:10.1016/S0109-5641(03)00065-4

15. Goracci C, Ferrari M. Current perspectives on post systems: a literature review. Aust Dent J. 2011;56:77-83. doi:10.1111/j.18347819.2010.01298.x

16. Gloria A, Maietta S, Martorelli M, Lanzotti A, Watts DC, Ausiello P. FE analysis of conceptual hybrid composite endodontic post designs in anterior teeth. Dent Mat. 2018;34(7):1063-1071. doi:10.1016/j. dental.2018.04.004

17. Grandini S, Goracci C, Monticelli F, Borracchini A, Ferrari M. SEM evaluation of the cement layer thickness after luting two different posts. J Adhes Dent. 2005;7(3):235-240.

18. Gomes GM, De Rezende EC, Gomes OMM, Gomes JC, Loguercio $\mathrm{AD}$, Reis A. Influence of the resin cement thickness on bond strength and gap formation of fiber posts bonded to root dentin. J Adhes Dent. 2014;16(1):71-78. doi:10.3290/j.jad.a30878

19. Kuttler S, Mc Lean A, Dorn S, Fischzang A. The impact of post space preparation with Gates-Glidden drills on residual dentin thickness in distal roots of mandibular molars. $J$ Am Dent Assoc. 2004;135:903-909. doi:10.14219/jada.archive.2004.0336

20. Grande NM, Butti A, Plotino G, Somma F. Adapting fiber-reinforced composite root canal posts for use in noncircular-shaped canals. Pract Proced Aesthet Dent. 2006;18(9):593-599.

21. Rocha AT, Gonçalves LM, Vasconcelos AJC, Matos Maia Filho E, Nunes Carvalho C, De Jesus Tavarez RR. Effect of anatomical customization of the fiber post on the bond strength of a self-adhesive resin cement. Int J Dent. 2017;2017:5010712. doi:10.1155/2017/ 5010712 
22. Tsintsadze N, Juloski J, Carrabba M, et al. Performance of CAD/ CAM fabricated fiber posts in oval-shaped root canals: an in vitro study. Am J Dent. 2017;30:248-254.

23. Ruse ND, Sadoun MJ. Resin-composite blocks for dental CAD/CAM applications. J Dent Res. 2014;93:1232-1234. doi:10.1177/00220345 14553976

24. Mangano F, Gandolfi A, Luongo G, Logozzo S. Intraoral scanners in dentistry: a review of the current literature. BMC Oral Health. 2017;17(1):149. doi:10.1186/s12903-017-0442-x

25. Mangano FG, Veronesi G, Hauschild U, Mijiritsky E, Mangano C. Trueness and precision of four intraoral scanners in oral implantology: a comparative in vitro study. PLoS One. 2016;11(9):e0163107. doi:10.1371/journal.pone.0163107

26. Mangano FG, Hauschild U, Veronesi G, Imburgia M, Mangano C, Admakin O. Trueness and precision of 5 intraoral scanners in the impressions of single and multiple implants: a comparative in vitro study. BMC Oral Health. 2019;19(1):101. doi:10.1186/s12903-0190792-7

27. Lee JH, Sohn DS, Lee CH. Fabricating a fiber-reinforced post and zirconia core with CAD/CAM technology. J Prosthet Dent. 2014;112:683-685. doi:10.1016/j.prosdent.2014.01.015

28. Liu P, Deng XL, Wang XZ. Use of a CAD/CAM-fabricated glass fiber post and core to restore fractured anterior teeth: a clinical report. J Prosthet Dent. 2010;103:330-333. doi:10.1016/S0022-3913(10) 60071-6

29. Chen Z, Li Y, Deng X, Wang X. A novel computer-aided method to fabricate a custom one-piece glass fiber dowel-and-core based on digitized impression and crown preparation data. J Prosthodont. 2014;23:276-283. doi:10.1111/jopr.2014.23.issue-4

30. Spina F, da Costa RG, Correr GM, Rached RN. Scanning of root canal impression for the fabrication of a resin CAD-CAM-customized postand-core. J Prosthet Dent. 2018;120(2):242-245. doi:10.1016/j.prosdent. 2017.08.009
31. Pinto A, Arcuri L, Carosi P, et al. In vitro evaluation of the post-space depth reading with an intraoral scanner (IOS) compared to a traditional silicon impression. Oral Implantol (Rome). 2017;10:360-368. doi:10.11138/orl/2017.10.4.360

32. Campanella V, Libonati A, Nardi R, et al. Single tooth anesthesia versus conventional anesthesia: a cross-over study. Clin Oral Investig. 2018;22:3205-3213. doi:10.1007/s00784-018-2413-2

33. Libonati A, Nardi R, Gallusi G, et al. Pain and anxiety associated with computer-controlled local anaesthesia: systematic review and meta-analysis of cross-over studies. Eur J Paediatr Dent. 2018;19 (4):324-332. doi:10.23804/ejpd.2018.19.04.14

34. Eid RY, Koken S, Baba NZ, Ounsi H, Ferrari M, Salameh Z. Effect of fabrication technique and thermal cycling on the bond strength of CAD/CAM milled custom fit anatomical post and core: an in vitro study. J Prosthodont. 2019;28(8):898-905. doi:10.1111/jopr.13101

35. Ferrini F, Sannino G, Chiola C, Capparè P, Gastaldi G, Gherlone EF. Influence of Intra-Oral Scanner (I.O.S.) in the marginal accuracy of CAD/CAM single crowns. Int J Environ Res Public Health. 2019;16 (4):E544. doi:10.3390/ijerph16040544

36. Ruschel GH, Gomes ÉA, Silva-Sousa YT, et al. Mechanical properties and superficial characterization of a milled CAD-CAM glass fiber post. J Mech Behav Biomed Mater. 2018;82:187-189. doi:10.1016/j.jmbbm.2018.03.035

37. Oguz Ahmet BS, Egilmez F, Ergun G, Cekic Nagas I. Surface treatment effects on bond strength of CAD/CAM fabricated posts to root canal dentin. Am J Dent. 2019;32(3):113-117.

38. Tsintsadze N, Juloski J, Carrabba M, et al. Effects of scanning technique on in vitro performance of CAD/CAM-fabricated fiber posts. J Oral Sci. 2018;60:262-268. doi:10.2334/josnusd.17-0254

39. Hayama H, Fueki K, Wadachi J, Wakabayashi N. Trueness and precision of digital impression obtained using an intraoral scanner with different head size in the partially edentulous mandible. $J$ Prosthodont Res. 2018;62:347-352. doi:10.1016/j.jpor.2018.01.003
Clinical, Cosmetic and Investigational Dentistry

\section{Publish your work in this journal}

Clinical, Cosmetic and Investigational Dentistry is an international, peer-reviewed, open access, online journal focusing on the latest clinical and experimental research in dentistry with specific emphasis on cosmetic interventions. Innovative developments in dental materials, techniques and devices that improve outcomes and patient

\section{Dovepress}

satisfaction and preference will be highlighted. The manuscript management system is completely online and includes a very quick and fair peer-review system, which is all easy to use. Visit http://www.dovepress.com/testimonials.php to read real quotes from published authors.

Submit your manuscript here: https://www.dovepress.com/clinical-cosmetic-and-investigational-dentistry-journal 